\title{
Circular Economy and Sustainability as a Basis for Economic Recovery Post-COVID-19
}

\author{
Javier Cifuentes-Faura ${ }^{1}$ (D
}

Received: 22 March 2021 / Accepted: 17 May 2021 / Published online: 25 May 2021

(C) The Author(s), under exclusive licence to Springer Nature Switzerland AG 2021

\begin{abstract}
The global COVID-19 crisis has led to a reduction in productive and commercial activity, as well as in the use of transport, which has led to a notable decrease in pollution levels. The paralysis of economic activity requires the commitment of government policies to impose economic recovery laws based on sustainability. The aim of this paper is to briefly review the situation that COVID-19 has caused in the environment and sustainability. In addition, a critical view of it is provided, and possible solutions for a sustainable economic reconstruction are offered. The coronavirus is revealing the fragility of the current economic system, based on profit and continuous consumption of resources. This model generates many problems such as pollution, contribution to climate change, loss of biodiversity or unfair distribution of wealth. This must be an opportunity to redefine the social purpose of business and help generate a sustainable world through economic policies. For economic recovery, a plan oriented towards energy and ecological transition and based on the circular economy must be followed.
\end{abstract}

Keywords COVID-19 · Environmental economics · Sustainability · Environmental policies · Circular economy

\section{Introduction}

Governments around the world have been reacting to the crisis caused by COVID-19 with similar measures such as house arrest and a corresponding halt in economic activity.

The social measures granted by the various governments are trying to avoid economic paralysis through fiscal aid and subsidies [1], although the health crisis threatens to cause an increase in the unemployment rate and an unprecedented economic recession throughout the world $[2,3]$.

Javier Cifuentes-Faura

javier.cifuentes@um.es

1 Faculty of Economics and Business, University of Murcia, Murcia, Spain 
The mistakes of the past must also be avoided. After the last economic crisis in $2008, \mathrm{CO}_{2}$ emissions soared, and inequalities deepened, demonstrating the need for reconstruction based on sustainable finance [4].

Today, there is a high risk that the urgency will lead to a relaunch of the economy in any way. In this context, and taking the experience of 2008 as a reference, it is essential to have the necessary means to ensure that public funds following COVID-19 contribute to achieving the Sustainable Development Goals (SDG).

As approved by the United Nations General Assembly in 2015, Agenda 2030 and the SDG must create the necessary conditions for sustainable, inclusive and sustained economic growth, where shared prosperity and decent work for all prevail and take into account the different national levels of development [5].

The problem will be if the way out of the health crisis is formulated solely in economic terms focused on the need to promote growth at any price, as there will be a rebound in $\mathrm{CO}_{2}$ emissions. The rise in emissions could even compensate for the reduction recorded during the containment phase. The aim must be to work on a recovery plan that integrates the ecological transition and the digital transformation as a basis for boosting this recovery.

This crisis must be a turning point to learn from the mistakes of the past. More investment must be made in essential public services that include humanitarian actions and the Sustainable Development Goals [6-8]. A change in thinking, values and actions will be needed from all professionals and social leaders, as well as from the general population [9].

The aim of this paper is to briefly review the situation that COVID-19 has created for the environment and sustainability. In addition, a critical view of it is provided, and possible solutions for a sustainable economic reconstruction are offered. The paper is structured as follows: the next section presents the situation that COVID-19 is causing in the environment and the need for an environmental economy, the third section shows measures to promote sustainable economic recovery and the last section presents the conclusions.

\section{Environmental Economics to Address COVID-19}

The coronavirus is revealing the fragility of the current economic system, based on profit and continuous consumption of resources. This model generates many problems such as pollution, contribution to climate change, loss of biodiversity or unfair distribution of wealth. Furthermore, the anthropocentric attitude of man towards nature influences the increase in pollution levels [10].

Teleworking and virtual meetings, as well as the cancellation of many public events, have led to a reduction in polluting gases in the atmosphere [11]. In addition, people staying at home during quarantine, less urban traffic and the stoppage of many industrial activities or construction sites, etc. have contributed to lower pollution levels [12-15].

This situation is shown in Fig. 1, which shows a significant drop in nitrogen dioxide $\left(\mathrm{NO}_{2}\right)$ in 2019 compared to 2020 in Wuhan, China, where the pandemic began.

This decrease in pollution levels has occurred globally. Proof of this is the significant drop in $\mathrm{NO}_{2}$ levels in five of the most important cities in Europe (Milan, Madrid, Paris, Berlin and Budapest) (Fig. 2). 


\section{Pollutant Drops in Wuhan-and Does not Rebound}

Unlike 2019, $\mathrm{NO}_{2}$ levels in 2020 did no: rise after the Chinese New Year.

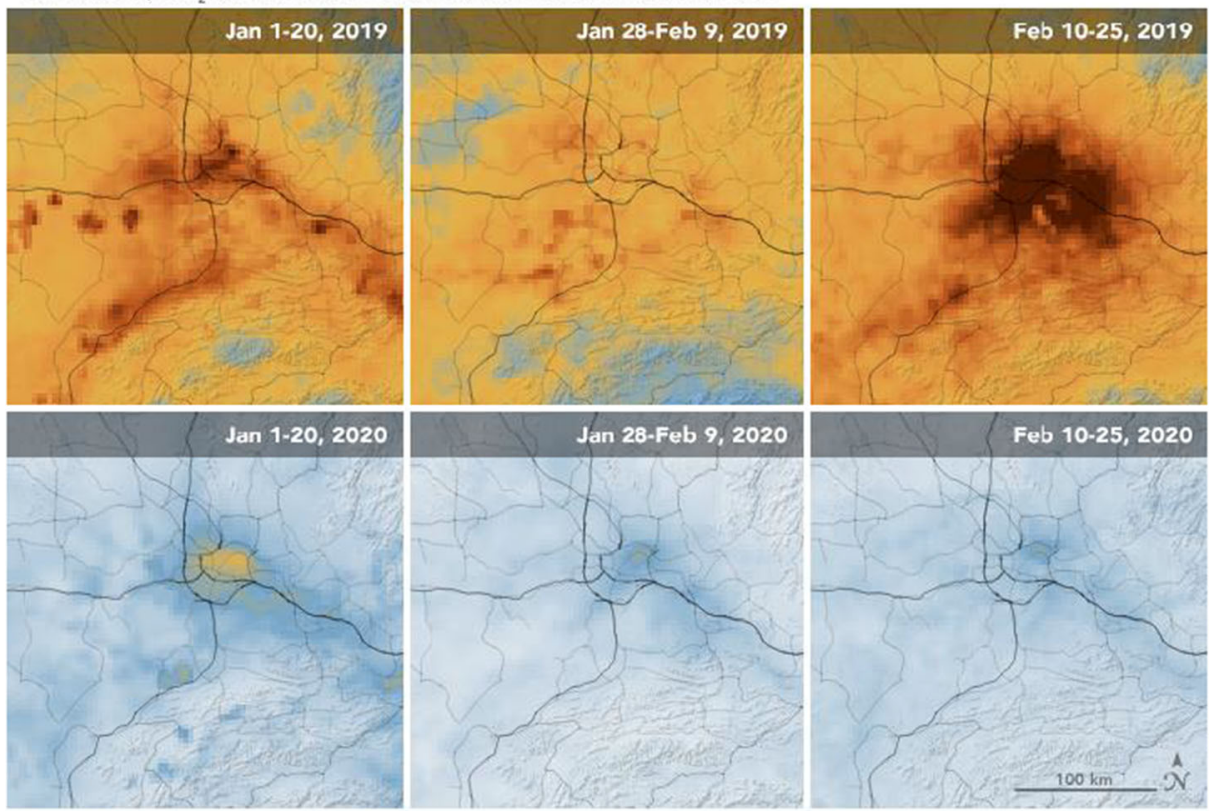

Mean Tropospheric $\mathrm{NO}_{2}$ Density $\left(\mu \mathrm{mol} / \mathrm{m}^{2}\right)$

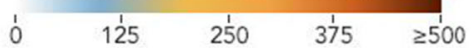

Fig. 1 Air pollution levels in Wuhan. Source: Earth Observatory NASA

The upper panel shows concentrations (using a 14-day moving average) in 2019 compared to 2020 using Sentinel-5P data, while the lower panel shows onsite observations. The Copernicus Sentinel-5P satellite [16] is part of the European Copernicus program and, since 2017, has been continuously monitoring changes in air pollution. A significant drop in
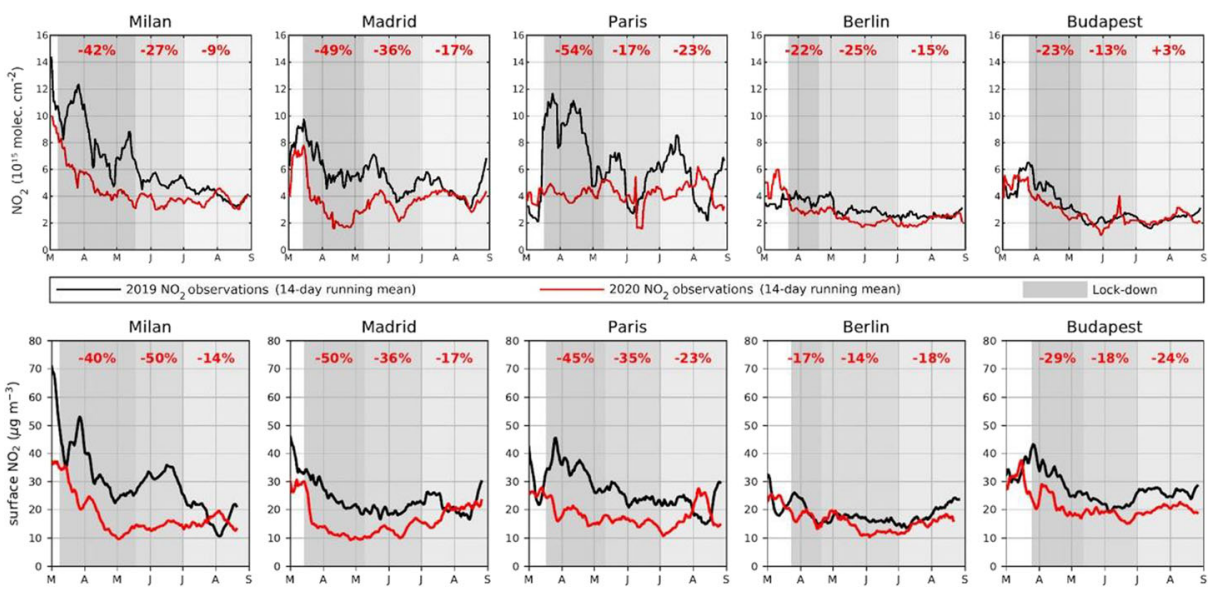

Fig. 2 Averaged nitrogen dioxide concentrations (2019 vs. 2020). Source: The European Space Agency 
pollution levels can be observed due to reduced activity in the industrial and energy sectors and reduced traffic.

However, this situation may only be temporary if the necessary measures for economic reconstruction are not taken. With the beginning of the recovery of economic activity, pollution levels increase [17].

Once this crisis is overcome, the risk to the environment lies in the possible relaxation of institutions in developing policies to combat air pollution, mitigate climate change or protect ecosystems. Environmental policies are often affected by the fear of limiting economic growth [18].

After the containment phase, there will be an increase in emissions during economic recovery, in response to increased production and mobility. China is the country where the coronavirus originated and where they have already begun the process towards economic recovery. This country is building new coal-fired power plants as a stimulus for its economy [19], which will make it difficult to reduce the problem of global warming. This situation will cause serious long-term damage to human beings, as it will lead to an increase in pollution levels. It is necessary to bet on green energies and to prioritize people's health in the face of future threats such as climate emergency or air pollution.

\section{Measures to Promote Sustainable Economic Recovery}

In order to try to reduce the environmental impact and to initiate the most environmentally sustainable ecological reconstruction possible, it is necessary to consider possible measures.

It is necessary to improve environmental health, since air or water pollution, in addition to causing a large number of premature deaths per year, undermines the health of the population and makes us more vulnerable to diseases such as COVID-19. Therefore, priority should be given in all public policies to actions that favour the environment.

We must not think that spending on the environment is a luxury that we can only afford in times of prosperity or economic surplus. Protecting and restoring functional and species-rich ecosystems is an investment that must be made to ensure human welfare and survival.

For economic recovery, a plan should be put in place that focuses on the energy and ecological transition and the digital transformation. A Green New Deal should be implemented to tackle climate change and transform the production model to make it more sustainable [20].

It is necessary to identify the destination of investments and the direction of reconstruction to promote the New Green Deal, so that recovery will involve renewal based on environmental sustainability, which would be an extraordinary source of creating employment and decent work. Jobs must be generated through the implementation of a circular economy model where investment is made in renewable and sustainable energies.

A model of the circular economy should be developed [21,22] to care for and preserve the environment through the implementation of sustainable strategies in the economy and society. It must be driven by different institutions and governments worldwide, to promote the decoupling of economic growth and increased resource consumption, maintaining the added value of products for as long as possible, while reducing waste to minimum levels. [23]. The circular economy model allows products to be used when they reach the end of their useful life through reuse $[24,25]$. 
Post-COVID-19 economic recovery programmes must encompass measures to address the climate crisis and the global loss of biodiversity. Several measures are suggested below to promote growth and economic recovery from an environmentally sustainable point of view:

- Ask financial institutions to increase lending to sustainable businesses through green credits.

- Make financial support for airlines or maritime transport conditional on the achievement of targets for reducing polluting emissions. Likewise, possible aid to the automobile sector should be conditioned to the promotion of environmental sustainability and the reduction of $\mathrm{CO}_{2}$ gases.

- Ensure, through audits, that spending on infrastructure is linked to energy efficiency, waste reduction, sustainable design and green technological innovation.

- Grant aid and subsidies to farmers according to their results in clean water and increased biodiversity. Those who practice more sustainable practices and pollute less will be eligible for more aid.

- Ban the use of stimulus package money to buy bonds issued by fossil energy companies.

Many of the services that are considered essential and that are of primary need for the confined society are related to natural resources and environmental services such as water supply, energy, waste collection and management or wastewater treatment. It is necessary and urgent to make a correct reconstruction of the planet, and we must all contribute and be part of it with a greater commitment. It is therefore essential to carry out economic recovery based on sustainability and where care for the environment plays a key role.

\section{Conclusions}

The most important long-term risks facing the global economy are related to climate change, both in terms of probability and economic severity. The circular economy takes on particular importance in the context in which we live. It can increase the capacity to adapt to crises and changes, making the economy more sustainable and competitive, minimising dependence on external suppliers and reducing the need for and impact of industrial transport.

A personal and collective commitment to coherence and social responsibility is needed to combat the socio-environmental crisis. It will be necessary to reduce consumption, purchase agro-ecological products, use the most sustainable public transport in each case or participate in the social and solidarity economy.

The Sustainable Development Goals of the United Nations Agenda 2030 are becoming fully applicable tools. The SDG are oriented, among others, to having public health systems, facing communicable diseases and their consequences, eradicating poverty, promoting decent work and orienting industrial and transport systems and consumption towards sustainable models. Those countries that were more oriented towards a path of compliance with the SDG and are closer to achieving those goals are those that will have better conditions for recovery.

Rebuilding economies to move towards sustainability is an opportunity that all countries must seize. Social dialogue and the Sustainable Development Goals that make up the United Nations Agenda 2030 are a necessary guide to solving current challenges.

Any positive environmental impact following COVID-19 must begin with a change in our production and consumption habits towards cleaner and more sustainable models. The long- 
term systemic transformations are the only ones that will change the trajectory of $\mathrm{CO}_{2}$ levels in the atmosphere. In the aftermath of this crisis, when economic stimulus packages are designed, there will be a real opportunity to meet that demand with sustainable plans for investments in renewable energy, smart buildings, sustainable vehicles or clean public transport.

An economy must emerge in which finance and action drive sustainable jobs, green growth and a different way of life, because the health of people and the health of the planet are linked, and one cannot survive without the other.

This COVID-19 pandemic should serve to show the clear connection between health and the environment and should make us aware that protecting the environment is probably the only strategy to avoid other health crises in the future.

Availability of Data and Material The author declares that all data and materials comply with field standards.

\section{Code Availability Not applicable}

\section{Declarations}

Conflict of Interest The author declares no competing interests.

\section{References}

1. Cifuentes-Faura $\mathbf{J}$ (2021) Analysis of containment measures and economic policies arising from COVID-19 in the European Union. Int Rev Appl Econ 35(2):242-255

2. Nicola M, Alsafi Z, Sohrabi C, Kerwan A, Al-Jabir A, Iosifidis C et al (2020) The socio-economic implications of the coronavirus and COVID-19 pandemic: a review. Int J Surg 78:185-193. https://doi. org/10.1016/j.ijsu.2020.04.018

3. Cifuentes-Faura, J. (2020). Crisis del coronavirus: impacto y medidas económicas en Europa y en el mundo. Espaço e Economia Revista brasileira de geografia econômica, (18) https://doi.org/10.4000/ espacoeconomia. 12874

4. Charan AS, Venkataraman H (2017) Greening the economy: a review of urban sustainability measures for developing new cities. Sustain Cities Soc 32:1-8

5. United Nations (2015). Resolution adopted by the general assembly 25 September 2015: transforming our world: The 2030 agenda for sustainable development. https://unctad.org/meetings/es/SessionalDocuments/ ares70d1_es.pdf. Accessed 30 Nov 2020

6. Balslev $\bar{H}$, García MAV (2019) Sustainable Development Goals and informal economies in Latin America: The bargaining power of informal economies in a sustainable context. Dialogos Latinoamericanos 28(20): $53-56$

7. Câmara JBD (2014) Reflections on the green economy (redemption of the principles of Mill and Pigou): a view of a Brazilian environmentalist. J Environ Prot 5(12):1153-1168

8. Ciocoiu CN (2011) Integrating digital economy and green economy: opportunities for sustainable development. Theoretical Empirical Res Urban Manag 6(1):33

9. Sachs J, Schmidt-Traub G, Kroll C, Lafortune G, Fuller G (2019) Sustainable Development Report 2019. Bertelsmann Stiftung and Sustainable Development Solutions Network (SDSN), New York, USA

10. Malone, K., Truong, S. (2017). Sustainability, education, and anthropocentric precarity. In Reimagining sustainability in precarious times (pp. 3-16). Springer, Singapore

11. Gautam S (2020) COVID-19: air pollution remains low as people stay at home. Air Qual Atmos Health 13: $853-857$

12. Nelson B (2020) The positive effects of covid-19. Bmj 369:m1785. https://doi.org/10.1136/bmj.m1785

13. Venter ZS, Aunan K, Chowdhury S, Lelieveld J (2020) COVID-19 lockdowns cause global air pollution declines. Proc Natl Acad Sci 117(32):18984-18990

14. Verma A, Prakash S (2020) Impact of covid-19 on environment and society. J Global Biosciences 9(5): $7352-7363$ 
15. Bashir MF, Jiang B, Komal B, Bashir MA, Farooq TH, Iqbal N, Bashir M (2020) Correlation between environmental pollution indicators and COVID-19 pandemic: a brief study in Californian context. Environ Res 187:109652

16. Vîrghileanu M, Săvulescu I, Mihai BA, Nistor C, Dobre R (2020) Nitrogen Dioxide (NO2) Pollution monitoring with Sentinel-5P satellite imagery over Europe during the coronavirus pandemic outbreak. Remote Sens 12(21):3575

17. Hoang, A. T., Huynh, T. T., Nguyen, X. P., Nguyen, T. K. T., \& Le, T. H. (2021). An analysis and review on the global NO2 emission during lockdowns in COVID-19 period. Energy Sources, Part A: Recovery, Utilization, and Environmental Effects, 1-21.

18. Cifuentes-Faura J (2021) COVID-19 and the opportunity to create a sustainable world through economic and political decisions. World J Sci Technol Sustain Dev. https://doi.org/10.1108/WJSTSD-12-2020-0100 ahead-of-print

19. Chu B, Zhang S, Liu J, Ma Q, He H (2021) Significant concurrent decrease in PM2. 5 and NO2 concentrations in China during COVID-19 epidemic. J Environ Sci 99:346-353

20. Sundaram JK (2020) Un Nuevo Acuerdo Verde Global (Global Green New Deal) para un desarrollo sostenible. El Trimestre Económico 87(345):279-291

21. Schroeder P, Anggraeni K, Weber U (2018) The relevance of circular economy practices to the Sustainable Development Goals. J Ind Ecol 23:77-95

22. Geissdoerfer M, Savageta P, Bockena NMP, Hultinkb EJ (2017) The circular economy—a new sustainability paradigm? J Clean Prod 143:757-768

23. Scarpellini S, Portillo-Tarragona P, Aranda-Usón A, Llena-Macarulla F (2019) Definition and measurement of the circular economy's regional impact. J Environ Planning and Manag IN PRESS 62:1-27. https://doi. org/10.1080/09640568.2018.1537974

24. Prieto-Sandoval V, Jaca C, Ormazabal M (2017) Economía circular: Relación con la evolución del concepto de sostenibilidad y estrategias Para su implementación [circular economy: Relationship with the evolution of the concept of sustainability and strategies for its implementation]. Memoria Investigaciones en Ingeniería:85-95

25. Rodriguez-Anton JM, Rubio-Andrada L, Celemín-Pedroche MS, Alonso-Almeida MDM (2019) Analysis of the relations between circular economy and sustainable development goals. Int J Sustain Dev World Ecol 26(8):708-720 